\title{
Ideational and ideomotor apraxia: a qualitative analysis
}

\author{
M.J. Mozaz \\ Facultad de Psicologia, Universidad del Pais Vasco, Aptdo. 1249, 20080 San Sebastian, \\ Guipuzcoa, Spain
}

\begin{abstract}
This paper reviews research into both ideational and ideomotor apraxia focusing on the qualitative aspects of limb apraxia. The criteria based on a distinction between different type of movements which have been used to distinguish between ideational (IA) and ideomotor apraxia (IMA) are reviewed together with an evaluation of the most frequent methods of testing and their effects on patients responses. Finally a list of the types of response reported in the literature is presented and their relationship with IA and IMA is proposed.
\end{abstract}

\section{INTRODUCTION}

The term apraxia was introduced at the end of the nineteenth century to refer to a wide variety of disorders such as asymbolia and agnosia (see Lange, 1985). The lack of precision in the use of the term led to much confusion in the study of disorders of voluntary movements. It was Liepman who first elaborated an anatomoclinical and psychopathological theory of apraxia (see Hecaen, 1981; Hecaen and Rondot, 1985) concluding that apraxia resulted from a subcortical lesion in the frontorolandic region or else from a left posterior parietal lesion. For Liepman, apraxia was a unitary phenomenon, the different varieties being the result of dysfunction of the same mechanism at different levels. He distinguished between the following types of limb apraxia (see Hecaen, 1981):

(a) Melokinetic apraxia involves the loss of kinetic engrams of special sections of the body. As a result movements are rough and awkward; it is however difficult to distinguish this from a mild form of paresis (De Renzi, 1989).

(b) Ideomotor apraxia involves a dissociation between optic, tactile and kinetic components of the different parts of the body which must work in cooperation with each other in order to produce a required movement.

(c) Ideational apraxia refers to disorders to the ideational plan of the movement. Although the kinetic component is intact the ideational component can be either loss (amnesic form) or impaired (see Lange, 1988).

After Liepman's classification other varieties of apraxia have been proposed; for example constructional apraxia, dressing apraxia, gait apraxia etc. This paper, however, will only consider two of the varieties proposed by Liepman, ideational (IA) and ideomotor (IMA) apraxia.

(C) 1992 Rapid Communications of Oxford Ltd
At present limb apraxia is defined as a disorder of the high level control of the execution of voluntary limb movements which cannot be explained by paresis, sensory impairment, disturbances in the coordination of movement, problems in understanding or by a severe mental deterioration (Poeck, 1985; Geschwind and Damasio, 1985; De Renzi, 1989). It is fairly well accepted that IA and IMA are independent of each other (De Renzi et al., 1968; Poeck and Lehmkuhl, 1980; Poeck, 1985; De Renzi, 1989) and result from the disruption of different mechanisms (De Renzi, 1989). Some authors however, (De Renzi et al., 1968; Poeck, 1985; De Renzi, 1989) have argued that IA and IMA may occur simultaneously in the same patient.

This paper concentrates on the qualitative aspects of limb apraxia. A critical review of the different criteria used to distinguish between IA and IMA is first presented together with an evaluation of the methods of testing. Then a list of the different types of responses showed by the patients as reported in the literature is considered and finally their relationship with IA or IMA is proposed.

\section{CRITERIA USED TO DISTINGUISH BETWEEN IA AND IMA}

A criterion very often used to distinguish between $\mathrm{AI}$ and IMA has been based on a distinction between different types of voluntary movements (i.e. transitive vs. intransitive movements or simple vs. complex gesture). Although the distinction between meaningful and meaningless movements has not been used to our knowledge to classify apraxia, it is important to have in mind that voluntary 
movements can also be both meaningful (i.e. gesture) and meaningless movements. A gesture may be defined as the result of a complex integration of an idea of the movement and of its execution in time and space (e.g. waving goodbye, hammering a nail). Gestures are learned patterns of behaviour, whilst meaningless movements (e.g. holding hand upright under the chin) could also be learned but, unlike gestures are not related to object manipulation or symbolic communication.

We shall next present a review of this types of voluntary movements and their relationship with IA and IMA as reported in the literature. We shall also discuss these criteria with reference to various methods of testing.

\section{Transitive vs. intransitive movements}

Transitive movements express an action that carries over from the subject to an object; for instance, hammering a nail. Intransitive movements express an action which does not carry over to an object. Intransitive movements can be both, meaningful (e.g. waving goodbye) or meaningless movements (e.g. holding hand upright under chin). The distinction between transitive and intransitive movements has been used to differentiate between IA and IMA. Some authors (Hecaen and Jeannerod, 1978; De Renzi et al., 1968; Agostini et al., 1983) consider ideomotor apraxia to be an impairment of the imitation of intransitive gestures (symbolic gestures and meaningless movements) whilst ideational apraxia has been considered by others to be an impairment of transitive movements, i.e. the use of objects (Ajuriaguerra et al., 1965; De Renzi et al., 1968; Heilman, 1973; Hecaen and Jeannerod, 1978; Agostoni et al., 1983). But, the inability to carry out pantomimes of intransitive gestures may sometimes be due to an ideational deficit, i.e. IA (De Renzi and Lucchelli, 1988) and the performance of both, transitive and intransitive meaningful movements on command involve both the ideational and the executive components of the movements (Barbieri and De Renzi, 1988). Some authors however, have reported dissocations between the performance on transitive and intransitive movements by apraxic patients (De Renzi and Lucchelli, 1988; Barbieri and De Renzi, 1988). There are two possible explanations of this discrepancy.

The first explanation refers to the methods of testing. Some authors require the patients to pretend to hold and use objects put on the table (comb, hammer, saw), but placed out of reach of the patient (De Renzi et al., 1988) while others show pictures of the objects (Duffy and Duffy, 1989). These procedures, elicits different mechanisms from those involved on purely verbal command. Thus it is necessary when analyzing the results that a comparison is made between scores obtained under the same conditions of performance. Mozaz (1986) carried out such an analysis and found no differences between the scores obtained by apraxic patients on symbolic gestures and object use gestures, on either verbal command or on imitation.

A second explanation for the inconsistent finding is based on the localization of the lesions. Roland et al. (1980a) found that supplementary motor and premotor areas are activated when voluntary movements are executed in intrapersonal space (which requires placing the hand and the arm in a particular relationship to the body; for instances salute, thumbing one's nose). Voluntary movements in extrapersonal space, which require the manipulation of objects, seem to be associated only with the activation of the parietal regions (Roland et al., 1980b). Hence different localization of the lesions could explain some of the discrepancy between the patients' performance on transitive and intransitive gestures.

\section{Simple vs. complex gestures}

Simple gestures refer usually to the use of one object whilst complex gestures, are those which involve the use of various objects. Thus ideomotor apraxia has been defined (Ajuriaguerra et al., 1960; Hecaen and Albert, 1978; Hecaen, 1981) as an impairment of the performance of simple gestures and ideational apraxia by contrast as the impairment of the performance of complex gestures (Ajuriaguerra et al., 1960; Hecaen and Albert, 1978; Hecaen, 1981; Poeck, 1982). However, doubt was cast on the validity of this criterion by Sittig who observed that even a simple gesture involves an ideational component (see De Renzi et al., 1968). This view was supported by a study (De Renzi et al., 1983) which found no significant differences between the performance of apraxic patients on simple gestures and their performance on complex gestures.

Mozaz (1986) found that only 3 out of 11 patients showed impairments in a test requiring the use of multiple objects but not in use of single objects; the remaining patients showed impairments on both types. In addition, a close correlation has been found (De Renzi and Lucchelli, 1988) between scores of a test requiring the use of a single object and that requiring the use of multiple objects. These authors claim that IA is not necessarily associated with complex actions. Indeed De Renzi (1989) suggests that the cause of failure in the use of both single and multiple objects is an inability to evoke the idea related to the use of the single object rather than a disorder in ordering the individual acts into a sequence. Some authors (Ochipa et al., 1989) identify IA with the use of single object, tool or instrument and others (Gonzalez Rothi et al., 1988; Rothi Gonzalez et al., 1988) have used the same test to disclose IMA, thus claiming that the single object test could be sensitive in identifying both IA and IMA.

This review shows that there are some reasons which 
rule out the possibility of considering the nature of the movements as a suitable criterion to classify apraxia into IA, IMA. First, the different types of movements overlap with each other. For instances, both transitive and intransitive movements can be simple (e.g. hammering a nail or waving goodbye, respectively) or complex (e.g. pantomime how to light a candle or the performance of alternative movements as opening right hand and making a fist with left, respectively). Again, as seen above intransitive movements can be both, meaningful (e.g. symbolic gestures as waving goodbye) or meaningless movements (holding hand upright under chin).

Also, the different methods of testing can elicit the ideational or executive component of the gestures, regardless of the nature of the gesture. Thus when subjects are asked to perform a gesture the question elicits complex cognitive mechanisms. These have been referred to as requiring a "conceptual level" (Heilman, 1979; Heilman et al., 1983) or the formation of a "gestema" (Signoret and North, 1979) or "plan of action" (Hecaen, 1981). Other authors refer to it as a "general gestural idea" (De Renzi et al., $1980,1982)$ and "selection of the elements which constitute a movement" (Poeck, 1985). All of these terms seem to appeal to an ideational component which could be loose in apraxic patients (Barbieri and De Renzi, 1988).

A verbal command to perform a gesture calls also for the execution of the corresponding internal model. Thus, if the ideational component is intact, performance is dependent on an adequate executive component. Thus when verbal comprehension is intact, poor performance may not be sufficient to determine whether the impairment occurs in the ideational, executive component or in both and an analysis of the responses under different methods of testing is therefore essential.

Imitation affects only the executive component, since the idea of plan of action is provided by the examiner. An incorrect imitation therefore would be consistent with an executive impairment, regardless of the possible preservation of the ideational component of the gestures. An adequate imitation, however, indicates the preservation of the executive component but, not necessarily of the ideational component. It is necessary in these cases to ascertain whether or not the patient recognize the gestures.

When handling an object, a correct demonstration of an actual object when the patient failed on command or imitation, indicates that there was not a motor deficit (Geschwind and Damasio, 1985) and that the impairment, related to limb apraxia was overcome by the possibility to use the real objects. An inadequate demonstration of the use of real objects, if there is not an object agnosia (Signoret, 1986) or an amnesia of usage (De Renzi and Lucchelli, 1988), suggests only the presence of limb apraxia. However, an analysis of the type of response shown by patients is essential in order to determine if the impairment is related to the ideational, executive or both components of the movement.

Thus from our point of view and regardless of the type of gestures or of their complexity, it is essential to ascertain whether the ideational, the executive or both components of the gesture are impaired. Hence an analysis of the different responses shown by patients in the different modes of examination may help to determine the presence of IA, IMA or both modalities together.

However a question to be solved is related to the mechanisms underlying IA. Barbieri and De Renzi (1988) state that IA is basically a form of semantic amnesia in which the patient is unable to evoke the form of the gesture or the way an object must be used (De Renzi, 1989), while Ochipa et al. (1989) consider ideational apraxia as a conceptual deficit. The process used to consolidate gestures in memory was found to be less efficient in apraxic than in non-apraxic patients (Gonzalez et al., 1985). It may occur, however, that both conceptual or a semantic amnesic deficits are responsible in different patients for IA. Thus, in order to ascertain whether in a particular apraxic patient a conceptual or semantic amnesic deficit exists, his ability to recognize both the gestures to be imitate and his own errors must be examined.

When a gesture performed by the examiner is correctly imitated by the patient but it is not recognized, and there is no perceptual deficit, we could be observing a case of agnosia for gestures (Gonzalez et al., 1986). When a gesture is incorrectly imitated but is recognized, the deficit may be an executive deficit. However, when the gesture, incorrectly performed on command or not performed at all, is correctly imitated and recognized, we must take into account the possibility that the disturbance might be related to semantic amnesia (De Renzi et al., 1988) which is overcome by the presentation of the model. It does not mean to say, however, that IA is necessarily the consequence of a general memory disturbance.

The patient's inability to recognize his own errors supports the view that a conceptual or a severe semantic amnesic deficit exists. But if the patient is able to recognize his own errors it would suggest that the problem maybe lies rather with the executive component.

\section{TYPES OF RESPONSES REPORTED IN THE LITERATURE}

A procedure which can be adopted when attempting to establish other possible criteria for classifying limb apraxia is based on the responses displayed by the patients.

Some authors have looked at the different types of error performed by apraxic patients, and have described the various errors shown by different groups of patients with cortical lesions (Goodglass and Kaplan, 1963; Roy and Square, 1985; Lehmkuhl et al., 1983; Ferro et al. 1983; 
Haaland and Flaherty, 1984; De Renzi and Lucchelli, 1988) and subcortical lesions (De Renzi et al., 1986; Basso et al., 1986; Rothi Gonzalez et al., 1988; Mozaz et al., 1990).

We present below a list of the types of responses that have been reported as this may help to distinguish between the varieties of limb apraxia seen in the clinic (Heilman et $a l ., 1985)$, and to determine whether lesions located in different areas may be associated with different types of errors (Gonzalez et al., 1988).

Amplitude (A). Includes any amplification or reduction of the standard amplitude of the gestures (Gonzalez Rothi et $a l ., 1988)$. It has been given different names: for instance, "gestural enhancement" (Goodglass and Kaplan, 1963), and "augmentation phenomenon" (Lehmkuhl et al., 1983; Poeck, 1986).

Clumsiness (CLS). Actions are conceptually appropriate but awkward, because of poor control of skilled hand movements (De Renzi and Lucchelli, 1988). A "timing" error (Gonzalez Rothi et al., 1988) could also be included in the present category.

Recognition but not imitation (RNI). The patients recognise the gestures but they are not able to imitate them (Mozaz, 1986).

Spatial orientation (SO). Involves arm and hand deviation from the normal position (Haaland and Flaherty, 1984).

Target $(T)$. The gesture is not performed on the correct body part (Haaland and Flaherty, 1984). For instance the patient touches the ipsilateral part of the body when imitating meaningless postures instead of touching the contralateral side (Mozaz et al., 1990). It has also been called "mislocation" (De Renzi and Lucchelli, 1988) when an action performed with an object is appropriate, but carried out at an inappropriate place (e.g. stuck the stamp on the back of the envelope).

Misuse (MIS). Objects are used in a conceptually inappropriate way, for instance, the bottle-opener was stirred inside the glass or a match is struck at the wrong end (De Renzi and Lucchelli, 1988).

Movement error (ME). Patients may, when demonstrating the use of a screwdriver, for instance, twist at shoulder instead of at the wrist. This response was reported by Gonzalez et al. (1988) as "M" (ECM) errors.

No response (NRS). See Gonzalez Rothi et al. (1988) and Roy and Square (1985).
"I do not know" (IDNK). The verbal response is given instead of the patients performing the movements they are asked to perform (Mozaz et al., 1990).

Imitation but no recognition (INR). (Gonzalez et al., 1986; Mozaz, 1986.)

Unrecognizable movement (UM). See Roy and Square (1985) or "amorphous movements" (Gonzalez et al., 1988).

Verbalization instead of performance (VIP). See Roy and Square (1985) and Mozaz et al. (1990) or "onomatopoetic response" (Geschwind and Damasio, 1985).

Parapraxia (PAX). Involves correct performance of gestures which had not been previously requested (Mozaz et al., 1991). They can be "related" (when is associated in content to the target, e.g. pantomime of playing a trombone for a target of a bugle) and "non-related" (e.g. pantomime of playing a trombone for a target of shaving) (Gonzalez Rothi et al., 1988).

Body part as object error (BPO). When pantomiming or imitating, patients use a part of their bodies as an object: for instance, use of index finger as a tooth-brush (Goodglass and Kaplan, 1963; Haaland and Flaherty, 1984; Geschwind and Damasio, 1985; Mozaz, 1986; Mozaz et al., 1990, Heilman et al., 1987, Gonzalez Rothi et al., 1988; Rothi Gonzalez et al., 1988; De Renzi and Lucchelli, 1988).

External configuration (EC). Involves abnormalities in considering the length of the object as for instance, the hand closed tightly into a fist with no space allowed for the imagined toothbrush handle (Gonzalez et al., 1988).

Internal configuration (IC). An error involving abnormalities of the finger/hand relationship to the target (Heilman et al., 1987; Gonzalez Rothi et al., 1988). Haaland and Flaherty (1984) called it BPO-2 (the hand is in the correct position to hold the object but the fist touches the target).

Irrelevant objects (IO). Involves patients using irrelevant objects to demonstrate the use of objects (Mozaz, 1986) as for instance, taking and using a pencil as a hammer when asked to pantomime a hammer. It also involves patients using irrelevant objects as support, as for example demonstrating the use of objects on the table (Ska and Nespoulous, 1987).

Demonstrating the use of objects on their own body $(D O B)$. When using real objects, patients demonstrate the 
use of objects on their own body as if the body represented the complementary object, as for instance demonstrate the use of the saw on the leg (Mozaz et al., 1990).

Perseveration (PER). Involves the repetition of a previously emitted response when a new response is intended or also the repetition of an action in which a subject is engaged (Sandson and Albert, 1984; Gonzalez Rothi et al., 1988; Roy and Square, 1985).

Omission (O). When the patient does not carry out an action necessary for completing a sequence. It has been called "fragmentary movement" (Poeck, 1986) or "occurrence" error (Gonzalez Rothi et al., 1988). It has also been described as "raising into position but not doing the movement" (Geschwind and Damasio, 1985). A type of error called "sequence error" (De Renzi and Lucchelli, 1988) implies that the omitted action is subsequently carried out spontaneously by the patient.

Delay (D). Delay in the initiation of a movement (Roy and Square, 1985; Gonzalez Rothi et al. 1988). It has also been called "perplexity" (De Renzi and Lucchelli, 1988) when patients give unmistakable signs that they don't know what to do but are eventually able to perform a movement, whether correct or not.

Vocal overflow (VO). Patients describe verbally, before being asked to, the movements they perform (Goodglass and Kaplan, 1963; Roy and Square, 1985; Mozaz, 1986). None of the authors who reported this response penalized it if the movements were well performed.

We shall focus next on the relationship between different types of responses to IA and IMA.

\section{TYPE OF ERRORS ASSOCIATED WITH IA AND IMA}

As an impairment of motor production IMA can be manifested by awkward execution of actions or poor orientation in space (De Renzi and Lucchelli, 1988). In contrast IA can be manifested by a loss of ideational component. Thus different types of responses could be related to one or another modality of limb apraxia. Table I shows the proposed association of responses with the individual forms of limb apraxia.

Looking at the list of the types of responses given above, responses such as "amplitude" (A), "clumsiness" (CLS), "recognition but not imitation" (RNI), "spatial orientation" (SO), "target" (T), "misuse" (MIS) and "movement errors" (ME) could all be considered as involving an executive deficit rather than an ideational deficit and therefore are associated with IMA when the general idea of the gesture seems to be preserved (see
TABLE I. Errors associated with IA and IMA

\begin{tabular}{ll}
\hline I. Ideomotor apraxic responses & \\
Amplitude & (A) \\
Clumsiness & (CLS) \\
Recognition but no imitation & (RNI) \\
Spatial orientation & (SO) \\
Target & (T) \\
Misuse & (M) \\
Movement error & (ME)
\end{tabular}

These responses on imitation may indicate a difficulty to benefit from the presentation of the model

\begin{tabular}{ll} 
II. Ideational apraxic responses & \\
(a) Total deficit & \\
No response & (NR) \\
I do not know & (IDNK) \\
Imitation but not recognition & (INR) \\
Unrecognisable movement & (UM) \\
Verbalisation instead of performance & (VIP) \\
Parapraxia & (PAX) \\
(b) Partial deficit & \\
Body part as object & (BPO) \\
External configuration & (EC) \\
Internal configuration & (IC) \\
Irrelevant objects & (IO) \\
Demonstrating the use of objects on the body & (DOB) \\
& \\
III. Unclassified & \\
Perseveration & (P) \\
Omission & (O) \\
\hline
\end{tabular}

Table I). However some qualifications are necessary: for instance, a "target" error, when the gesture is not performed on the correct body part, could be the result of both a general spatial orientation deficit or a body schema disorientation. The issue can only be settled by examining the patients' body schema.

Errors labelled "no response" (NRS) or absence of execution, "I don't know" (IDNK), "imitation but not recognition" (INR), "no recognition of errors" (NRE), "unrecognisable movement" (UM), "verbalization instead of performance" (VIP) and "parapraxia" (PAX), related and non-related, are responses which can be consistent with an ideational deficit.

"No response" (NRS) is not considered as a paramount feature of apraxia (Poeck, 1986), although some authors (Roy and Square, 1985) argue that it is one of the most frequent type of errors in patients with limb apraxia. In general "no responses" are considered to be associated (Ochipa et al., 1989) with IA (see Table I).

One of the most common responses reported in the literature "body part as object" (BPO) has been associated with ideomotor apraxia (Gonzalez Rothi et al., 1988; Ochipa et al., 1989). There is a further problem, not only with BPO but also the related responses "external con- 
figuration" (EC), "internal configuration" (IC), "taking irrelevant objects to demonstrate the use of objects" (IO) and "demonstrating the use of objects on one's own body" (DOB) which seem to have something in common with BPO. They may indicate different manifestations of impairment of the propositional use of objects (DennyBrown, 1956) or of differentiation between self and objects. BPO responses are common for the 4-year-old child while "external configuration" errors (EC), are considered a less primitive error which is more commonly made by 8 -year-old (Haaland and Flaherty, 1984). The differentiation between self and objects involves a cognitive component (Piaget, 1962), and it is difficult therefore to associate these types of responses exclusively with a motor production deficit and for this reason they have been included as a partial ideational deficit (Table I).

There are several responses which are difficult to categorize as having an ideational or only an executive component. For instance, it has been suggested (Roy and Square, 1985), that "perseveration" (PER) does not always involve the persistence of the "idea" of the previous action, and can be exclusively a motor phenomenon. "Omission" $(\mathrm{O})$ responses seems to be the result of a partial ideational deficit but, as "perseveration" they also could indicate an execution deficit. "Perseveration" or "omission" responses on command may not be sufficient to ascertain whether the deficit is related to an ideational or an executive component. Thus the imitation method of testing is essential. If patients benefit from imitation it would suggest a semantic amnesic deficit overcome by the presentation of the model. If he does not benefit from imitation and does not recognize the error, it could be related to an ideational deficit. But, if the patient recognizes it, they could be due to an executive deficit.

Finally there are some responses such as "delay" (D) and "vocal overflow" (VO) which are not considered as errors if the gesture is nevertheless correctly performed. However "vocal overflow" has been considered as a possible prerequisite for the occurrence of BPO responses (Goodglass and Kaplan, 1963) because it indicates that the subject has difficulty in separating the representation of the pretended action from his immediate involvement in the action.

To conclide, the type of unsuccessfully performed gesture cannot any longer be considered as a valid criterion for classifying limb apraxia into IA and IMA. The review emphasizes the importance of an analysis of the responses to the different methods of testing in patients with limb apraxia in order to ascertain the presence of IA and IMA.

\section{Acknowledgements}

The authoress would like to thank Dr M.A. Wyke for her helpfull discussions and comments on the paper. We would also like to thank Universidad del Paris Vasco for their support.

\section{REFERENCES}

Agostoni E, Colett A, Orlando G and Tredigi G (1983). Apraxia in deep cerebral lessions. Journal of Neurology, Neurosurgery and Psychology, 46, 804-808.

Ajuriaguerra J, Muller M and Tissot R (1960). A propos de quelques problémes poses par l'apraxia dans les démences. $L$ 'Encéphale, 5, 375-401.

Ajuriaguerra J, Kluser JP, Velghe J and Tissot R (1965). Prixies idéatoires et permanence de l'objet. Quelgues aspects de leur desintégration conjointe dans les syndromes démentielles du grand âge. Psychiatry and Neurology, 150, 236-319.

Barbieri C and De Renzi E (1988). The executive and ideational components of apraxia. Cortex, 24, 535-543.

Basso A and Della Salla (1986). Ideomotor apraxia arising from a purely deep lesion. Journal of Neurology, Neurosurgery and Psychiatry, 49, 458-465.

De Renzi E, Pieczuro A and Vignolo LA (1968). Ideational apraxia: a quantitative study. Neuropsychologia, 6, 41-52.

De Renzi E, Motti F and Nichelli P (1980). Imitating gestures: a quantitative approach to ideomotor apraxia. Archives of Neurology, 37, 6-10.

De Renzi E, Faglioni P and Sorgato P (1982). Modality specific and supramodal mechanisms of apraxia. Brain, 105, 301-312.

De Renzi E, Faglioni P, Lodesani M and Vecchi A (1983). Performance of left brain-damaged patients on imitation of single movements and motor sequences. Frontal and parietal injured patiens compared. Cortex, 19, 333-343.

De Renzi E, Faglioni P, Scarpa M and Grisi G (1986). Limb apraxia in patients with damage confined to the left basal ganglia and thalamus. Journal of Neurology, Neurosurgery, and Psychiatry, 49, 1030-1038.

De Renzi E and Lucchelli F (1988). Ideational apraxia. Brain, 111, 1173-1185.

De Renzi E (1989) Apraxia. In: Handbook of Neuropsychology, Vol. 2 (Eds F Boller and J Grafman). Elsevier, Amsterdam.

Denny-Brown D (1958). The nature of apraxia. Journal of Nervous and Mental Disorders, 126, 9-33.

Duffy RJ and Duffy JR (1989). An investigation of body part as object (BPO) responses in normal and brain-damaged adults. Brain and Cognition, 10, 220-236.

Ferro JM, Martins IP, Mariano G and Castro Caldas A (1983). CT scan correlates off gesture recognition. Journal of Neurology, Neurosurgery, and Psychiatry, 46, 943-952.

Geschwind N and Damasio AR (1985) Apraxia. In: Handbook of Clinical Neurology, Vol. 1, Clinical Neuropsychology (Ed. JAM Frederiks), pp. 423-432.

Gonzalez L, Heilman KM and Watson R (1985). Pantomime comprenhension and ideomotor apraxia. Journal of Neurology, Neurosurgery, and Psychiatry, 48, 207-210.

Gonzalez L, Mack L and Heilman KM (1986). Pantomime agnosia. Journal of Neurology, Neurosurgery, and Psychiatry, 49, 451-454.

Gonzalez Rothi LJ, Mack L, Verfaellie M, Brown P and Heilman K (1988). Ideomotor apraxia: error pattern analysis. Aphasiology, 2, 381-388.

Goodglass H and Kaplan E (1963). Disturbance of gesture and pantomime in aphasia. Brain, 26, 703-720.

Haaland KY and Flaherty D (1984). The different types of limb apraxia errors made by patients with left vs. right hemisphere damage. Brain and Cognition, 3, 370-384.

Hecaen H and Albert ML (1978). Disorders of gestural behavior. The apraxias. In: Human Neuropsychology (Eds H Hecaen and ML Albert), pp. 91-127. Wiley, New York. 
Hecaen H (1981). Apraxias. In: Handbook of Clinical Neuropsychology (Eds SB Filsko and TL Boll), Chap. 8, pp. 257-286. Irving B Wernies and Senis, New York.

Hecaen $\mathrm{H}$ and Rondot $\mathrm{P}$ (1985). Apraxia as a disorder of a system of signs. In: Neuropsychological Studies of Apraxia and Related Disorders (Ed. EA Roy). Elsevier/North-Holland, Amsterdam.

Hecaen H and Jeannerod M (1978). Du Control Moteur a l'Organisation du Geste. Masson, Paris.

Heilman KM (1973). Ideational apraxia. A redefinition. Brain, 96, 861-864.

Heilman KM (1979). Apraxia. In: Clinical Neuropsychology (Eds KM Heilman and E Valenstein). Oxford University Press, New York.

Heilman KM, Rothi L and Kertesz A (1983). Localization of apraxia producing lessions. In: Clinical Neuropsychology (Eds M Heilman and E Valenstein). Oxford University Press, New York.

Heilman K, Rothi L and Kertesz A (1985). Localization of apraxia producing lesions. In: Clinical Neuropsychology (Eds M Heilman and E Valenstein). Oxford University Press, New York.

Heilman K, Mack L, Rothi L and Watson R (1987). Transitive movements in a deafferented man. Cortex, 23, 525-530.

Lange J (1988) Apraxia. In: Agnosia and Apraxia: selected papers of Liepmann, Lange, and Pötzl (Ed. JW Brown). Lawrence Erlbaum, London.

Lehmkuhl G, Poeck K and Willmes K (1983). Ideomotor apraxia and aphasia: an examination of types and manifestations of apraxics symptoms. Neuropsychologia, 21, 199-212.

Mozaz M (1986). Aspectos semiológicos de las apraxias de los miembros superiores. Resum de la tesi per assolir el grau de Doctor en Psicologia. Universitat de Barcelona, Centre de Publicaciones.

Mozaz M, Martí JF and Carrera E (1990). Apraxia in a patient with right subcortical lesion. Analysis of errors. Cortex, 26, 651-655.

Mozaz M, Wyke M and Indakoetxea B (1991). Apraxia in a patient with lesion located in right sub-cortical area. Analysis of errors. Journal of Neurology, Neurosurgery, and Psychiatry, 26, 651-655.

Ochipa C, Rothi LJG and Heilman KM (1989). Ideational apraxia: a deficit tool selection and use. Annals of Neurology,
25, 190-193.

Piaget J (1962). Play, Dreams and Imitation in Childhood. Routledge \& Kegan Paul, London.

Poeck K and Lehmkuhl, G (1980). Ideatory apraxia in a lefthanded patient with right-sided brain lesion. Cortex, 16, 273-284.

Poeck K (1982). The two varieties of motor apraxia. Archs Italia Biologica, 120, 361-369.

Poeck K (1985). Clues to the nature of disruptions to limb apraxias. In: Neuropsychological Studies of Apraxia and Related Disorders (Ed. EA Roy), pp. 99-109. Elsevier/North-Holland, Amsterdam.

Poeck K (1986). The clinical examination for motor apraxia. Neuropsychologia, 24, 129-134.

Roland PE, Larsen B, Lassen NA and Skinhoj E (1980a). Supplementary motor area and other cortical areas in organization of voluntary movements in man. Journal of Neurophysiology, 43, 118-136.

Roland PE, Skinhoj E, Larsen B and Lassen NA (1980b). Different cortical areas in man in organization of voluntary movements in extrapersonal space. Journal of Neurophysiology, 43, 137-150.

Rothi Gonzalez LJ, Koistra C, Heilman K and Mack L (1988). Subcortical ideomotor apraxia. Abstract of a poster presented at the 16th Annual INS Meeting. Journal of Clinical and Experimental Neuropsychology, 10, 48.

Roy EA and Square PA (1985). Common considerations in the study of limb, verbal and oral apraxia. In: Neuropsychological Studies of Apraxia and Related Disorders (Ed. EA Roy), pp. 111-161. Elsevier/North-Holland, Amsterdam.

Sabourad OL (1976). Des l'importance d'une boîte à outils pour examiner les malades atteinst d'unelesion corticale. Livre Jubilaire du Pro, pp. 255-260. Girard, Lyon.

Sandson J and Albert ML (1984). Varieties of perseveration. Neuropsychologia, 22, 715-732.

Ska B and Nespoulus J-L (1987). Pantomimes and aging. Journal of Clinical and Experimental Neuropsychology, 9, 754-766.

Signoret JL and North P (1979). Les apraxies gestuelles. Congrès de Psychiatrie et du Neurologie de Langue Francaise. Masson, Paris.

Signoret JL (1986). Visual agnosia for objects. In: Neurology (Eds K Poeck, HJ Freund and H Gäns). Springer, Berlin. 


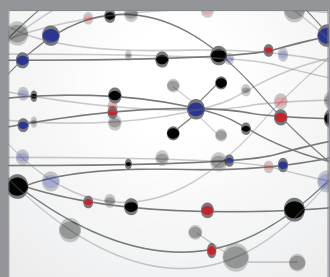

The Scientific World Journal
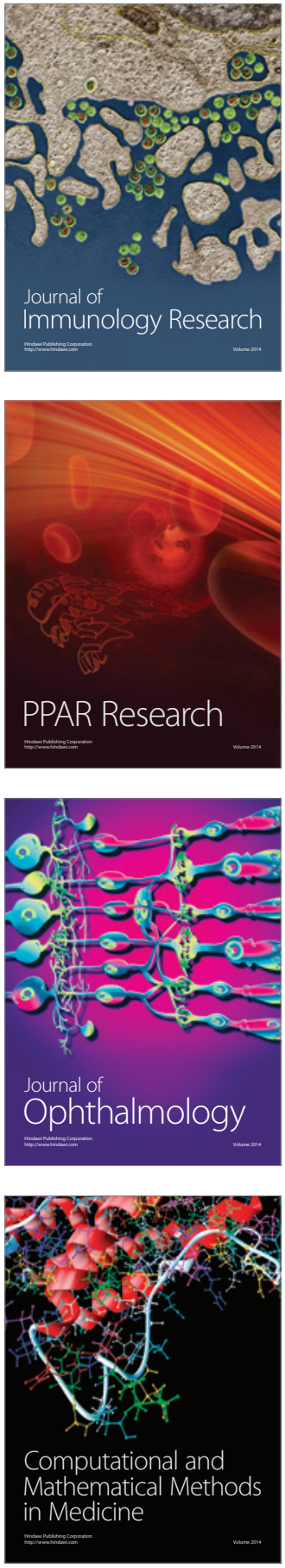

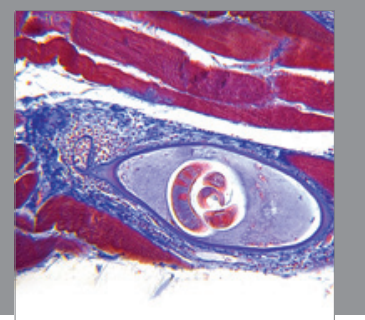

Gastroenterology

Research and Practice
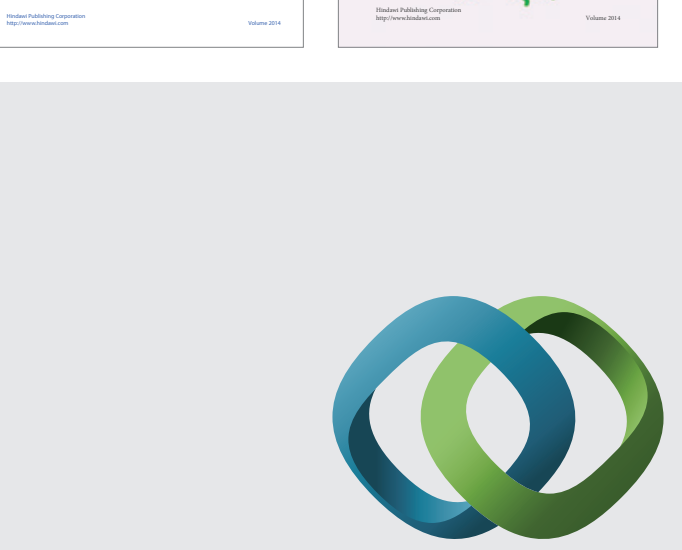

\section{Hindawi}

Submit your manuscripts at

http://www.hindawi.com
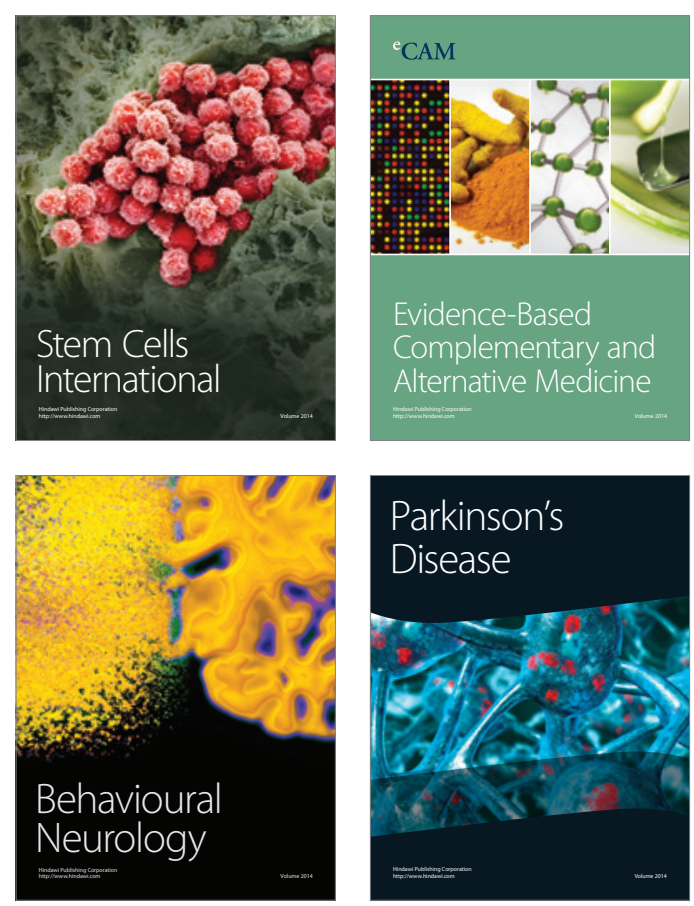

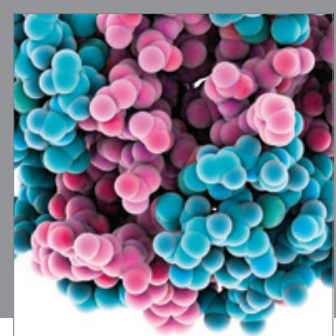

Journal of
Diabetes Research

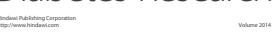

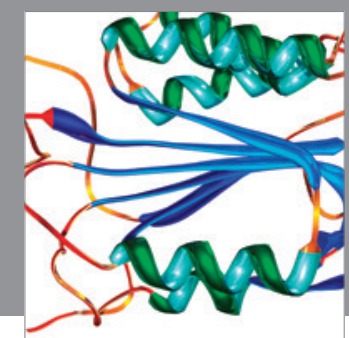

Disease Markers
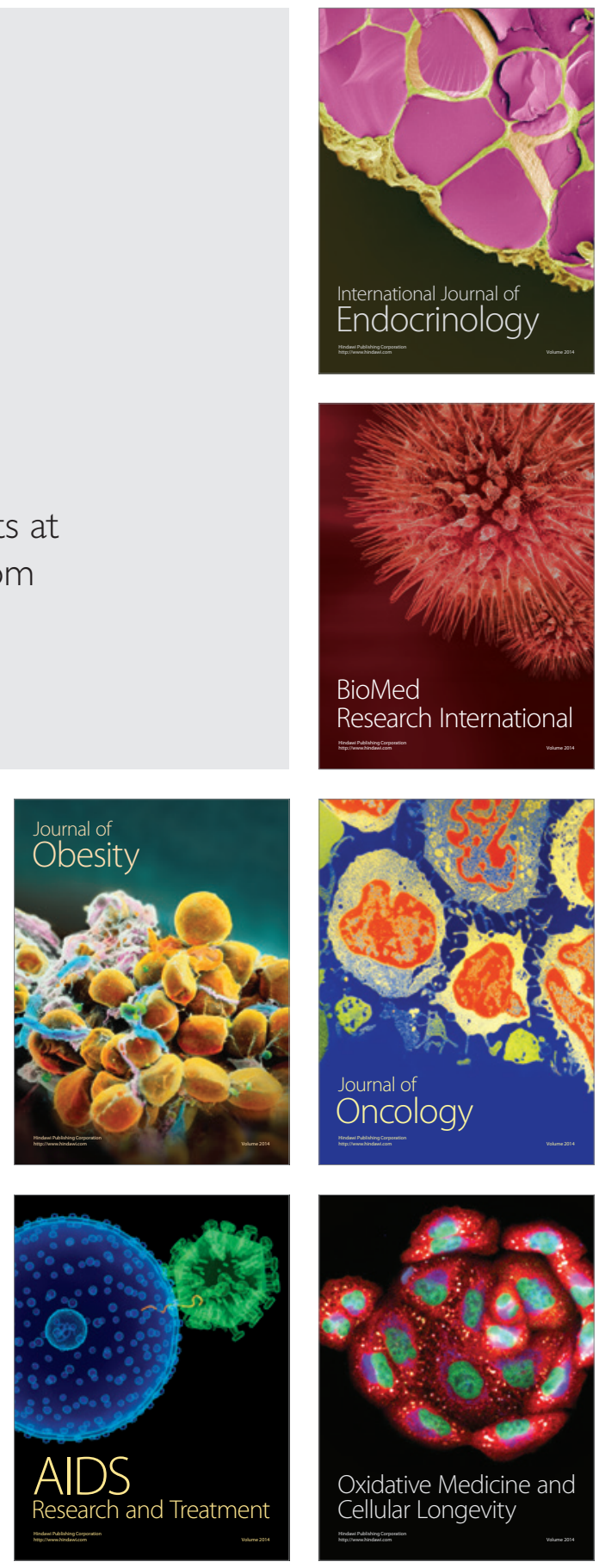